\title{
O SERVIÇO SOCIAL NA RESIDÊNCIA MULTIPROFISSIONAL EM ONCOLOGIA NO INSTITUTO NACIONAL DE CÂNCER - INCA ${ }^{1}$
}

\author{
THE MULTIDISCIPLINARY RESIDENCY SOCIAL WORK IN ONCOLOGY AT THE \\ NATIONAL CANCER INSTITUTE - INCA
}

Letícia Batista Silva ${ }^{2}$

Márcia Valéria de Carvalho Monteiro ${ }^{3}$

Maria Conceição Barbosa dos Santos ${ }^{4}$

Fernanda dos Reis Melo ${ }^{5}$

Eliane da Silva Estalino ${ }^{6}$

\section{RESUMO}

O presente artigo tem como objetivo apresentar a contribuição do Serviço Social na implantação do Programa de Residência Multiprofissional em Oncologia do Instituto Nacional de Câncer. Toma a questão do câncer como problema de saúde pública e entende como estratégico o ensino em serviço na modalidade residência multiprofissional. O texto reafirma os princípios basilares do Sistema Único de Saúde e busca discutir a importância da reflexão crítica acerca dos determinantes sociais no processo saúde/doença, apresentando essa como uma contribuição do Serviço Social.

PALAVRAS-CHAVE: Serviço Social. Residência Multiprofissional. Saúde. Oncologia.

\section{ABSTRACT}

This article has as its goal presenting the Social Work contribution at the implementation of the Multidisciplinary Residency Program on Oncology of the National Cancer Institute. It takes the issue of Cancer as matter of public health and understands as a strategy the education in service process at the multidisciplinary Residency mode. The text reaffirms the basic principles of the Brazilian Health System (SUS) and seeks to discuss the importance of the critical reflections concerning the social determinants to the health/disease process, presenting it as a contribution of Social Work.

KEYWORDS: Social Work. Multidisciplinary Residency. Health. Oncology.

\footnotetext{
${ }^{1}$ Instituto Nacional de Câncer - INCA

${ }^{2}$ Assistente social do INCA, Mestre em Serviço Social (UFRJ), Doutoranda em Serviço Social (UERJ), tutora e preceptora do Programa de Residência Multiprofissional em Oncologia (INCA). Telefone: 21 988787708, e-mail: leticiabatista@gmail.com.

${ }^{3}$ Assistente social do INCA, Mestre em Serviço Social (PUC/RJ), tutora e preceptora do Programa de Residência Multiprofissional em Oncologia (INCA). E-mail: marciamonteiro.as@hotmail.com.

${ }^{4}$ Assistente Social do INCA, Mestre em Educação Profissional em Saúde (EPSJV/FIOCRUZ) Tutora e Preceptora do Programa de Residência Multiprofissional em Oncologia (INCA). E-mail: mcbarbosa_santos@yahoo.com.br.

${ }^{5}$ Assistente social do INCA, Mestre em Saúde Pública (ENSP/FIOCRUZ), Coordenadora da Área de Serviço Social no Programa de Residência Multiprofissional em Oncologia (INCA). E-mail: femelo@ig.com.br.

${ }^{6}$ Assistente social do INCA, Coordenadora da Área de Serviço Social no Programa de Residência Multiprofissional em Oncologia do INCA, Especialização em Serviço Social em Oncologia (INCA). E-mail: estalino@terra.com.br.
} 


\section{INTRODUÇÃO}

O adoecimento por câncer ${ }^{7}$ é considerado um problema de saúde pública mundial. A Organização Mundial da Saúde (OMS) estimou, para o ano 2030, 27 milhões de casos, sendo apontados maiores índices de mortalidade para os países periféricos (WHO, 2008).

No Brasil, o câncer é a segunda causa de morte da população. A Estimativa 2012², válida também para o ano de 2013, aponta 518.510 casos novos de câncer, reiterando o câncer como questão de saúde púbica. São estimados um total de 257.870 casos novos para o sexo masculino e 260.640 para o sexo feminino. A partir desses dados infere-se que o câncer - do diagnóstico ao tratamento oncológico - perpassa todos os níveis de complexidade do Sistema Único de Saúde (SUS), exigindo um conjunto articulado e contínuo de ações. Neste sentido a Residência Multiprofissional em Oncologia apresenta-se como um potencial articulador de diferentes saberes e intervenções no campo da Oncologia, visando à integralidade das ações.

Em 2005, a Lei Federal nº 11.129/05 instituiu as residências multiprofissionais e em área profissional da saúde. Tais programas abrangeram as profissões da área da saúde: Biomedicina, Ciências Biológicas, Educação Física, Enfermagem, Farmácia, Fisioterapia, Fonoaudiologia, Medicina Veterinária, Nutrição, Odontologia, Psicologia, Serviço Social e Terapia Ocupacional (conforme Resolução CNS nº 287/1998). Também nesta Lei foi criada, no âmbito do Ministério da Educação, a Comissão Nacional de Residência Multiprofissional em Saúde (CNRMS), cuja organização e funcionamento foram disciplinados em ato conjunto dos Ministros de Estado da Educação e da Saúde.

Dando seguimento às regulamentações da Residência Multiprofissional, destacase a Resolução CNRMS n 2, de 13 de abril de 2012. Esta legislação específica, dentre outras questões: institui as diretrizes gerais para a criação e a operacionalização dos Programas de Residência Multiprofissional e em Área Profissional da Saúde, em âmbito nacional; reitera que os Programas de Residência Multiprofissional e em Área Profissional da Saúde serão orientados pelos princípios e diretrizes do SUS, a partir das

${ }^{7}$ O câncer é entendido como um conjunto de mais de 100 doenças, causado pela reprodução desordenada de células malignas, podendo ter variadas causas externas e/ou internas (INCA, 2012).

${ }^{8}$ Esta publicação é realizada a cada dois anos pelo Instituto Nacional do Câncer, sempre com base nas informações geradas pelos Registros de Câncer de Base Populacional (RCBP). Neste texto são apresentados os dados da Estimativa 2012, publicada no ano de 2011.

Serv. Soc. \& Saúde, Campinas, SP v. 11, n. 1 (13), p. 51-66 jan./ jun. 2012 ISSN 1676-6806 
necessidades e realidades locais e regionais identificadas; define que a residência multiprofissional constitui modalidade de ensino de pós-graduação lato sensu, destinada às profissões da saúde, excetuada a área médica, sob a forma de curso de especialização, caracterizado por ensino em serviço, com carga horária de 60 (sessenta) horas semanais, com duração mínima de 02 (dois) anos e em regime de dedicação exclusiva. Para ser caracterizado como Residência Multiprofissional em Saúde, o programa deverá ser constituído por, no mínimo, 03 (três) profissões da saúde; define que as instituições que oferecerem Programas de Residência Multiprofissional e em Área Profissional da Saúde serão responsáveis pela organização do Projeto Pedagógico (PP) dos respectivos programas de pós-graduação; define também que os programas poderão ser desenvolvidos a partir de áreas de concentração ${ }^{9}$.

A Residência Multiprofissional em Oncologia instituiu-se tendo a questão do câncer como área de concentração.

A partir do exposto, o presente artigo propõe-se a discutir a implantação dessa modalidade multiprofissional de ensino em serviço no Instituto Nacional de Câncer José de Alencar $^{10}$ (INCA), destacando a participação e a contribuição do Serviço Social neste processo.

\section{O Programa de Residência Multiprofissional em Oncologia do INCA: questões sobre o Ensino em Serviço}

Criado em 1937 na cidade do Rio de Janeiro, o INCA é o órgão auxiliar do Ministério da Saúde no desenvolvimento e na coordenação das ações integradas para a prevenção e o controle do câncer no país. Tais ações compreendem a assistência

hospitalar ${ }^{11}$, prestada direta e gratuitamente aos usuários adoecidos por câncer, como

\footnotetext{
${ }^{9}$ Conforme o Art. $4^{\circ}$, § $4^{\circ}$ da Resolução CNRMS 2/2012, entende-se como área temática um conjunto de áreas de concentração que inclui um núcleo específico de saberes e práticas com afinidade programática, e pelos quais as perspectivas de integração multidisciplinar e interdisciplinar podem ser desenvolvidas por meio de estratégias de organização dos serviços e do processo de ensino/aprendizagem para a implementação dos programas, conforme normatizados pelas Câmaras Técnicas da CNRMS.

10 O INCA recebeu esta denominação em 2011.

11 O INCA é constituído de 05 (cinco) unidades hospitalares: Hospital do Câncer I, que congrega o maior número de especialidades oncológicas, dentre elas: cabeça e pescoço, neurologia, abdômen, tórax, urologia, hematologia adulto e infantil, oncologia pediátrica e oncologia clínica; Hospital do Câncer II, unidade que atua com as clínicas de ginecologia oncológica, tecido ósseo conectivo e oncologia clínica; Hospital do Câncer III, responsável pelo atendimento aos casos de câncer de mama; Hospital do Câncer IV, unidade especializada em cuidados paliativos; e o CEMO, com atuação em transplante de medula óssea.

Serv. Soc. \& Saúde, Campinas, SP v. 11, n. 1 (13), p. 51-66 jan./ jun. 2012 ISSN 1676-6806
} 
parte dos serviços oferecidos pelo SUS; e também a atuação em áreas estratégicas, como prevenção e detecção precoce, formação de profissionais especializados, desenvolvimento da pesquisa e geração de informação epidemiológica.

Destacando as atividades de ensino, o Programa de Residência Multiprofissional em Oncologia do INCA teve sua primeira turma em 2010, constituída de 06 (seis) categorias profissionais: assistentes sociais, enfermeiros, farmacêuticos, nutricionistas, fisioterapeutas e odontólogos. No ano de 2011, a Psicologia foi acrescida ao rol das profissões do Programa.

O Plano de Curso do Programa de Residência Multiprofissional em Oncologia, consolidado pela representação de todas as categorias profissionais envolvidas, ao abordar acerca da questão pedagógica destaca que,

A proposta pedagógica do Programa fundamenta-se em uma base conceitual, filosófica e metodológica que parte da análise dialética das transformações sociais e do mundo do trabalho no contexto histórico atual - a Educação Problematizadora. Sua abordagem pedagógica parte do empírico (vivência) para o mediatizado (reflexão e ação - práxis); não separa método, teoria e prática; privilegia o educando como sujeito do processo ensino-aprendizagem, a diversificação dos cenários de aprendizagem, o uso de metodologias ativas e a avaliação formativa (INCA, 2012, p.5).

Não obstante o avanço formal que significa a construção e a instituição de tais parâmetros para fundamentar a Residência Multiprofissional em Oncologia e seus sentidos pedagógicos, trata-se de um desafio a materialização desta proposta, pois demanda importantes alterações no cotidiano da instituição, entendendo que neste espaço correlaciona a prática profissional e as atividades de ensino e pesquisa.

Como questões a serem superadas no que se referem ao processo de formação, o Plano do Programa destaca os seguintes itens:

1. A substituição do modelo de ensino centrado no professor por atividades de aprendizagem centradas na reflexão sobre a realidade, de maneira a articular teoria e prática;

2. A superação do modelo disciplinar fragmentado pela construção de um currículo interdisciplinar, no qual o eixo da formação articula processos de ensino, pesquisa, 
gestão e assistência em equipe multiprofissional, tendo a integralidade do cuidado como tema transversal;

3. A mudança da concepção de saúde como ausência de doenças para a de saúde como qualidade de vida;

4. O rompimento com a polarização entre individual versus coletivo e biológico versus social;

5. A mudança da concepção de avaliação como processo punitivo para a de avaliação inclusiva, diagnóstica e processual.

Neste sentido é objetivo geral do Programa capacitar profissionais da área da saúde para atuarem na Rede de Atenção Oncológica, nas atividades de assistência, ensino, pesquisa e gestão, em uma perspectiva interdisciplinar e de acordo com os princípios do SUS. Entendendo-se que a atenção oncológica se estende da Atenção Básica às unidades de alta complexidade. Deste modo, o Programa de Residência Multiprofissional em Oncologia possibilita a formação de profissionais de saúde para atuarem em diferentes níveis de atenção do SUS - ação esta que vem ao encontro, não só do controle e combate ao câncer, mas também, da qualificação do trabalho em Saúde no seu sentido amplo.

Sobre o perfil geral do egresso, espera-se a constituição de:

Profissional de saúde crítico-reflexivo, com base no rigor científico e intelectual, para atuar de forma integral e interdisciplinar na Atenção Oncológica (Atenção Básica, de Média e de Alta Complexidades) em diferentes modalidades: promoção da saúde, prevenção de agravos, rastreamento, detecção precoce, diagnóstico, tratamento, reabilitação e cuidados paliativos. Traz no escopo de sua atuação os aspectos éticos, legais e humanísticos para a assistência, o ensino, a pesquisa e a gestão, frente às necessidades dos usuários do SUS, considerando as características sociais, culturais, subjetivas, espirituais e também epidemiológicas (INCA, 2012, p.10).

As discussões no âmbito da Oncologia estão inscritas nos debates gerais acerca do Sistema de Saúde brasileiro. A regulamentação do SUS, a partir da década de 1990 no Brasil, trouxe significativas mudanças tecnológicas, organizacionais e políticas, que passaram a exigir novas formas de organização do trabalho no campo da saúde, provenientes da hierarquização, descentralização e democratização, princípios deste Sistema.

Assim, a trajetória da Saúde no país tem promovido contemporaneamente a necessidade de formação de profissionais críticos e reflexivos, que, principalmente, Serv. Soc. \& Saúde, Campinas, SP v. 11, n. 1 (13), p. 51-66 jan./ jun. 2012 ISSN 1676-6806 
acompanhem o processo de modificações e transformações das estruturas de atenção à saúde coletiva, individual e a gestão do processo de trabalho para a efetivação e melhoria das políticas públicas em saúde. Para tanto, aqui também fica evidenciado o imperativo que articula trabalho/prática e educação/ensino.

Atenção à Saúde demanda a organização estratégica do sistema e das práticas de saúde em resposta às necessidades da população. É expressa em políticas, programas e serviços de saúde consoantes aos princípios e às diretrizes que estruturam o SUS. Considera-se que a atenção à saúde se remete tanto a processos históricos, políticos e culturais, que expressam disputas por projetos no campo da saúde, quanto à própria concepção de saúde sobre o objeto e os objetivos de suas ações e serviços, isto é, o que e como devem ser as ações e os serviços de saúde, assim como a quem se dirigem, sobre o que incidem e como se organizam para atingir seus objetivos.

Dessa forma, destaca-se o programa de educação pelo trabalho, ação de caráter intersetorial entre o Ministério da Saúde e o Ministério da Educação, que firma parcerias entre estas políticas sociais na constituição do Programa de Residência Multiprofissional em Oncologia que tem por objetivo a formação de um contingente profissional adequado às necessidades atuais da saúde coletiva que se traduzem interdisciplinarmente.

Tomando como base as colocações de Donnangelo (1976), que afirma ser o trabalho em saúde uma prática social e não somente uma prática técnica, e de Abrahão (2007) que aponta para o enfoque estritamente biológico que tem sido direcionado à formação dos trabalhadores para a saúde; e, correlacionando tais perspectivas e com base no cotidiano das práticas em saúde, infere-se que a formação profissional para esta área não tem respondido às suas necessidades sociais. Necessidades estas emergentes do modo de produção capitalista. Este modelo de formação profissional - de cunho biologicista - tem se referenciado, de modo restrito, na busca eficiente de evidências ao

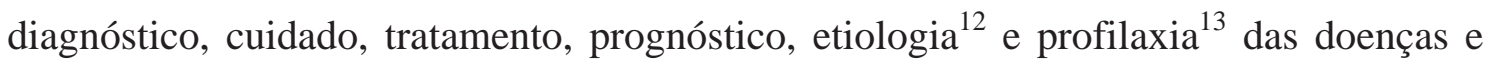
agravos.

Assim, pode-se afirmar que a educação dos trabalhadores na saúde é composta por projetos contraditórios, conflitantes e em luta por uma visão de mundo. É na área de Educação em Saúde, entendida como campo privilegiado para a construção de saberes e

\footnotetext{
12 Estudo das origens de um fenômeno, causa de uma doença, estudo das causas da doença.

${ }^{13}$ Emprego de qualquer procedimento ou agente para evitar instalação e/ou propagação de doença.

Serv. Soc. \& Saúde, Campinas, SP v. 11, n. 1 (13), p. 51-66 jan./ jun. 2012 ISSN 1676-6806
} 
práticas de educação em serviço, que se estabelecem relações sociais cotidianas entre os profissionais de saúde no âmbito institucional.

Pensar saúde e educação no Brasil significa refletir sobre a evolução histórica de uma sociedade desigual. Ao identificar semelhanças entre a organização do sistema de saúde e o sistema de educação, Teixeira (1992) estabelece um paralelo entre essas duas políticas, compondo um quadro das condições sob as quais os dois sistemas operam: a) multiplicidade de instituições com ações desordenadas; b) superposição e irracionalidade na distribuição da rede de serviços; c) seletividade e exclusão da população mais pobre, com concentração da rede nas áreas urbanas mais ricas; d) centralização e burocratização da administração dos serviços; e) programação verticalizada; f) ausência de controle da produção de insumos; ao contrário, a produção passa a determinar o modelo de atenção; g) não valorização dos profissionais; h) não participação da comunidade (TEIXEIRA, 1992, p. 27-37).

Desta forma, não cabe mais pensar estas políticas sociais, especialmente a Saúde e a Educação, como instâncias isoladas de um todo, ou de uma maneira abstrata, desvinculando-as de um contexto econômico, político e social que integram e do qual são resultantes. Ressalta-se, portanto, a lógica da organização dos serviços em saúde, centrada na produtividade de seus procedimentos técnico-operativos, e a lógica do trabalho da instituição formadora, centrada na produção de seus conhecimentos teóricos e metodológicos dos campos pedagógicos e núcleos específicos.

Tal desarticulação entre teoria e prática suscita a reflexão crítica de que a prática se torna uma exigência da relação teoria/prática, sem a qual a teoria pode ir transformando-se em falácia, e a prática, em ativismo. Quando a integração ensinoserviço acontece de forma efetiva, unindo docentes, preceptores e discentes, e cujo foco central está no usuário, esta dicotomia entre o ensino e a produção dos cuidados em saúde é amenizada.

Espera-se que a integração ensino, aprendizagem e trabalho coletivo produza ações pactuadas e integradas entre educandos, preceptores, equipes e gestores da saúde, visando à qualidade da atenção à saúde individual e coletiva, da formação profissional e à satisfação de seus trabalhadores. A abordagem pedagógica deve considerar os atores envolvidos como sujeitos deste processo e as estratégias pedagógicas devem ser capazes de utilizar e promover cenários de aprendizagem configurados em itinerários de linhas 
de cuidado, de forma a garantir a formação integral e interdisciplinar e, sobretudo, a criação de vínculos efetivos de corresponsabilização com o processo de saúde/doença.

\section{O SERVIÇO SOCIAL NA RESIDÊNCIA MULTIPROFISSIONAL EM ONCOLOGIA}

A Saúde, em particular na área da Oncologia, reflete diferentes expressões da questão social ${ }^{14}$ no Brasil, visto que, para segmentos significativos da população, o próprio adoecimento é a manifestação direta da precariedade das condições de vida, das dificuldades de acesso às ações de prevenção primária e secundária, da desarticulação entre os níveis de atenção em saúde e da fragilidade (fragmentação e focalização) das políticas de proteção social no país.

Sendo assim, desvendar o objeto de trabalho pelo qual o assistente social atua, ou seja, conhecer como a questão social se manifesta no cotidiano dos sujeitos sociais é essencial para o desenvolvimento de um processo consistente, equânime e integral de atenção em saúde.

Do ponto de vista de seu Projeto Ético Político, a prática dos assistentes sociais na Saúde está articulada à defesa do SUS, portanto, intrinsecamente identificada com seus princípios fundamentais, dentre os quais cumpre destacar: a universalidade do acesso em todos os níveis de assistência; a integralidade, articulando continuamente ações preventivas e curativas; a equidade, tratando de forma desigual os desiguais, a fim de construir uma efetiva e real igualdade em saúde; e o controle social, entendendo que os usuários são sujeitos atuantes e reconhecidos pelo sistema de saúde.

O processo de implantação e consolidação do SUS, no entanto, tem sido notoriamente marcado por uma série de obstáculos, contradições e desafios, tais como: a subordinação à lógica econômica gerando contenção de gastos e desfinanciamento, a falta de equidade na alocação dos recursos públicos em razão da falta de unificação dos orçamentos das três esferas de governo, a prioridade para a assistência médicohospitalar em detrimento das ações de promoção e proteção da saúde (BRAVO, 2006). Questões que apontam para o atravessamento de interesses antagônicos no setor saúde ou, conforme aponta Bravo (2006), para a existência de dois projetos que convivem em tensão: o Projeto de Reforma Sanitária, entendendo a saúde como política social pública, universal e integral; e o Projeto Privatista, vinculado ao mercado, pautado na

\footnotetext{
14 Questão social, conforme define lamamoto (2006), entendida como fruto das desigualdades
} sociais e das contradições da sociedade capitalista.

Serv. Soc. \& Saúde, Campinas, SP v. 11, n. 1 (13), p.51-66 jan./ jun. 2012 ISSN 1676-6806 
política de ajuste de corte neoliberal, e propondo ao Estado o atendimento mínimo e focalizado aos segmentos populacionais mais empobrecidos, e, ao mesmo tempo, estimulando o seguro privado em saúde.

Este contexto impacta na vida dos usuários do SUS gerando cotidianamente fraturas na universalidade do acesso, na integralidade das ações e na igualdade da assistência. A articulação com o Projeto de Reforma Sanitária aponta para uma prática profissional dos assistentes sociais em defesa do aprofundamento e da construção cotidiana do sistema de saúde, e para o compromisso com a proposição, formulação e efetivação de estratégias e experiências que consolidem o direito social à saúde universal.

Ora, o reconhecimento da saúde como um direito social pressupõe a superação da perspectiva biomédica - centrada na concepção de saúde como ausência de doenças, bem como a incorporação da compreensão de saúde como resultado das condições de vida da população, conforme definido na Lei Orgânica da Saúde (Lei nº 8.080/90):

A saúde tem como fatores determinantes e condicionantes, entre outros, a alimentação, a moradia, o saneamento básico, o meio ambiente, o trabalho, a renda, a educação, o transporte, o lazer e o acesso aos bens e serviços essenciais; os níveis de saúde da população expressam a organização social e econômica do país (BRASIL, 1990).

Assim definida, a concepção ampliada de saúde está imbricada à noção de determinação social ao sustentar-se nas categorias trabalho e reprodução social da vida como fatores determinantes das condições de saúde. Neste sentido, as necessidades de saúde da população ultrapassam o nível de acesso a serviços e tratamentos médicos, e somente podem ser compreendidas como produtos das relações sociais e destas com os meios físico, social e cultural. Conforme apontam Nogueira e Mioto (2006), dentre os diversos fatores determinantes das condições de saúde incluem-se os condicionantes biológicos, o meio físico, assim como os meios socioeconômico e cultural. Descrevem as autoras:

Dentre os diversos fatores determinantes das condições de saúde incluem-se os condicionantes biológicos (idade, sexo, características herdadas pela herança genética), o meio físico (que inclui condições geográficas, características da ocupação humana, disponibilidade e qualidade de alimento, condições de habitação), assim como os meios socioeconômico e cultural, que expressam os níveis de ocupação, renda, acesso à educação formal e ao lazer, os graus de liberdade, hábitos e formas de relacionamento interpessoais, a possibilidade de acesso aos serviços voltados para a promoção e recuperação da saúde 
e a qualidade da atenção pelo sistema prestado (NOGUEIRA; MIOTO, 2006, p. 229).

No campo da Oncologia tais aspectos adquirem expressão tanto no risco ao adoecimento por câncer, quanto nas condições de acesso da população ao diagnóstico precoce e ao tratamento da doença. Embora o risco do adoecimento por câncer esteja associado a uma multiplicidade de fatores que vão da susceptibilidade genética às condições resultantes do modo de vida e do ambiente (BRASIL, 2006), as determinações sociais e econômicas são particularmente relevantes no que se referem às condições que viabilizam o acesso à detecção e ao tratamento precoce e adequado da doença.

Dentre os condicionantes socioeconômicos que atravessam o processo de adoecimento e o tratamento oncológico, destacam-se: as condições de acesso à rede SUS para diagnóstico; as condições de acessibilidade ao centro especializado de tratamento - considerando-se as necessidades de transporte, hospedagem e alimentação mediante a distância entre o local de moradia e o centro de tratamento; a manutenção dos meios de subsistência, trabalho e renda; a manutenção dos vínculos sociais e familiares; a relação entre as condições de moradia e as necessidades de cuidado requeridas pelo tratamento, no que se refere às dimensões do imóvel, localização, infraestrutura e saneamento básico - não podemos deixar de mencionar a falta de políticas sociais públicas que respondam efetiva e eficazmente a tais demandas ${ }^{15}$. A estas questões, dentre outras que emergem cotidianamente mediante a complexidade da vida social, somam-se a vulnerabilização e a fragilização física provocada pelo adoecimento por câncer e pelos efeitos e sequelas de seu tratamento ${ }^{16}$, geralmente invasivos e mutilantes.

Este contexto influencia todo o processo saúde/doença, devendo ser assimilado pelas equipes de saúde na construção das propostas de cuidado em Oncologia, na perspectiva de superar a fragmentação da atenção, considerando o usuário e a família

\footnotetext{
${ }^{15}$ Apenas para ressaltar que no contexto neoliberal de retração das políticas sociais públicas, os programas implementados têm caráter focalista e seletivo e, sendo assim, não atendem às necessidades dos usuários e de suas famílias.

${ }^{16} \mathrm{O}$ tratamento de câncer envolve quimioterapia, radioterapia e cirurgia, isoladas ou combinadas. Dependendo do estadiamento da doença, do tipo e localização do tumor, o tratamento pode levar a sequelas e mutilações severas e irreversíveis. Além disso, trata-se de tratamento longo e continuado que tem por característica a centralização do espaço hospitalar na vida do indivíduo acometido pela doença, bem como a de seu cuidador/familiar, o que produz interferências no cotidiano de suas relações sociais, particularmente no que se refere ao trabalho, renda e família.
}

Serv. Soc. \& Saúde, Campinas, SP v. 11, n. 1 (13), p. 51-66 jan./ jun. 2012 ISSN 1676-6806 
como sujeitos do processo, o que requer práticas interdisciplinares e ações intersetoriais, como caminhos para o efetivo exercício da integralidade.

Neste aspecto, há que se ressaltar que o entendimento ampliado do processo de saúde/doença é fundamental na formação não só dos assistentes sociais, mas na de todos os profissionais que compõem as equipes de saúde, bem como o caráter necessariamente coletivo do enfrentamento das expressões da questão social na particularidade brasileira no campo da saúde.

Nesta compreensão dos processos sociais, reside uma das principais contribuições do Serviço Social no Programa de Residência Multiprofissional em Oncologia: a partir do conhecimento das condições de vida e trabalho dos usuários, bem como da compreensão dos determinantes sociais que interferem no processo saúde/doença, a discussão crítica junto aos usuários, demais categorias profissionais da saúde e gestores, acerca de como estes irão impactar no processo de cuidados ao usuário/paciente no curso do tratamento oncológico. Se o conceito ampliado de saúde requer o trabalho coletivo, neste processo o assistente social dispõe de um lugar privilegiado, visto que é o profissional que irá intervir com o objetivo de compreender os aspectos sociais, econômicos e culturais que interferem no processo saúde/doença e de buscar estratégias para o enfrentamento destas questões (BRAVO; MATOS, 2006).

Tendo por base estes parâmetros gerais que ancoram o fazer profissional na saúde, entendendo o Serviço Social como profissão de cunho interventivo e o campo da Oncologia como área de atenção em saúde que demanda o atendimento integral e práticas integradas e intersetoriais, delineia-se o perfil e as competências do egresso assistente social na residência multiprofissional do INCA. Desta forma, o perfil do egresso assistente social foi assim definido:

Profissional reconhecidamente defensor do acesso ao SUS, identificado com a prática interdisciplinar no cuidado integral em saúde. Suas ações devem estar fundamentadas no Projeto Ético Político do Serviço Social que se volta para o compromisso com a população usuária da atenção oncológica. Tem intrínseco em suas práticas em saúde a divulgação dos direitos sociais como a estratégia para ampliação das políticas públicas sociais e do controle social em saúde (INCA, 2012, p. 52)

Partindo desta compreensão, as competências do egresso do Serviço Social no INCA, definidas no Plano de Curso do Programa e construídas com base nos princípios 
do Projeto Ético Político Profissional ${ }^{17}$, apontam para contribuições profissionais específicas e também para a construção de ações sociais coletivas que vislumbrem uma ordem societária democrática. As competências identificadas abaixo apresentam as definições elencadas no plano de curso (INCA, 2012):

1. Defender, de forma intransigente, os princípios do SUS: público, universal, equânime e de qualidade;

2. Atuar em equipe multiprofissional, na perspectiva interdisciplinar, buscando a construção do cuidado integral em oncologia;

3. Atuar em equipe multiprofissional, desvelando os determinantes da questão social no adoecimento e no tratamento oncológico;

4. Contribuir para a viabilização da participação efetiva da população usuária nas decisões institucionais;

5. Garantir a plena informação e discussão sobre as possibilidades e consequências das situações apresentadas, respeitando democraticamente as decisões dos usuários, mesmo que sejam contrárias aos valores e às crenças individuais dos profissionais;

6. Democratizar as informações e o acesso aos direitos, políticas e programas disponíveis no espaço intra e extra institucional;

7. Atuar com vistas à defesa e à ampliação dos direitos sociais dos usuários;

8. Estimular e promover o controle social nas práticas em saúde;

9. Prestar assistência ao paciente na perspectiva de atenção integral, a partir de uma abordagem interdisciplinar;

10.Desenvolver ações educativas nas abordagens individuais e coletivas;

11. Refletir, de forma interdisciplinar, acerca das contradições de ordem ética e bioética emergidas do cotidiano da equipe multiprofissional e dos usuários;

12.Desenvolver práticas integradas, buscando ampliar a qualidade da assistência ao paciente oncológico nos diversos níveis de atenção do SUS;

13. Desenvolver e divulgar projetos de gestão, intervenção, ensino e pesquisa;

14.Desenvolver atividades técnico-científicas em oncologia, desempenhando ações no âmbito da assistência, do ensino e da pesquisa, pautando-se no Projeto Ético Político do Serviço Social;

15. Instrumentalizar os usuários para a busca e efetivação dos direitos sociais, potencializando e respeitando a autonomia desses sujeitos.

Desta forma, a perspectiva de compreensão do Serviço Social busca fortalecer as diretrizes do programa de Residência Multiprofissional do INCA, assim como possibilitar mudanças no modelo técnico assistencial, a partir de uma perspectiva interdisciplinar e da compreensão de que as ações que vão ao encontro do controle e do combate ao câncer exigem a adoção orgânica da compreensão do conceito ampliado de saúde e o exercício da transversalidade das políticas públicas e sociais.

\footnotetext{
${ }^{17}$ Tem por base o Código de Ética do Serviço Social (1993), a Lei de Regulamentação da Profissão de Assistente Social (1993) e a Lei de Diretrizes Curriculares da ABEPSS (1996).
}

Serv. Soc. \& Saúde, Campinas, SP v. 11, n. 1 (13), p. 51-66 jan./ jun. 2012 ISSN 1676-6806 
Cabe destacar que a operacionalização destas diretrizes no cotidiano institucional se dá através da inserção dos residentes, pautada nos Parâmetros para Atuação de Assistentes Sociais na Política de Saúde (CFESS, 2010), que se materializam nas seguintes ações: na realização de entrevistas para a coleta de dados e informações socioeconômicas; em sua participação em rounds ${ }^{18}$, discussões de casos e sessões clínicas, observando e interagindo com as ações da equipe de saúde, bem como fomentando informações acerca do contexto social dos usuários que se façam necessárias à condução do processo de tratamento; na coordenação dos grupos educativos nos espaços ambulatoriais e nas enfermarias junto aos usuários adoecidos, familiares e cuidadores e/ou responsáveis, na perspectiva de socializar informações para o acesso aos direitos sociais oriundos das políticas sociais públicas e promover o conhecimento da dinâmica institucional; na participação em mesas redondas ${ }^{19}$, identificando as situações que demandam intervenção do Serviço Social de forma a viabilizar o plano de tratamento; na integração aos dispositivos da Política Nacional de Humanização, contribuindo com o conhecimento específico do Serviço Social no plano de tratamento dos usuários, bem como subsidiando o gerenciamento dos processos, visando os fundamentos do SUS e não na perspectiva de diminuição dos conflitos entre usuário e instituição; na interlocução e na articulação da rede socioassistencial; dentre outras ações.

As competências apresentadas no Programa de Residência Multiprofissional no INCA demonstram que o mesmo conquistou avanços na sua formatação, porém, ainda evidenciam-se dilemas e desafios no processo de construção e implementação do curso, que precisam ser superadas, dentre os quais destacamos: as dificuldades na liberação das atividades da assistência para a realização das atividades de ensino; o desenvolvimento de ações que propiciem a superação da hegemonia das práticas assistenciais; o exercício permanente do diálogo entre coordenadores, docentes, tutores e preceptores das áreas específicas que se encontram no campo operacional com as demais categorias profissionais no processo de organização das práticas integradas e dos conteúdos teóricos dos eixos transversais; a não integração da residência médica ao Programa; a garantia do saber específico na direção de um saber compartilhado, não

\footnotetext{
${ }^{18}$ Reuniões interdisciplinares diárias que ocorrem nas enfermarias com o objetivo de socialização e discussão da situação de saúde e tratamento do usuário internado e definição de condutas.

${ }^{19}$ Reuniões multiprofissionais, na maioria das vezes sem a presença do usuário adoecido, para a discussão de propostas de tratamento.

Serv. Soc. \& Saúde, Campinas, SP v. 11, n. 1 (13), p. 51-66 jan./ jun. 2012 ISSN 1676-6806
} 
renunciando às especificidades do conhecimento do Serviço Social no programa de ensino multiprofissional; a garantia do processo de educação permanente em saúde para os preceptores; a padronização na condução das práticas assistenciais e dos processos de gestão nas unidades assistenciais, legitimando o programa de ensino multiprofissional no INCA; a implementação de um conjunto de ações voltadas para a participação de usuários, familiares e profissionais de saúde em espaços de controle social.

Neste contexto, torna-se um grande desafio para a prática em saúde o desenvolvimento de programas de ensino e pesquisa que se processem no âmbito do cotidiano, já que as práticas assistenciais são, historicamente, hegemônicas na profissão e no campo da saúde. Assim, aos atores sociais envolvidos nestes processos preceptores, tutores, supervisores, orientadores e residentes - cabe o desafio de implementarem ações que visem, sobretudo, instrumentalizar as suas práticas na perspectiva de superação do pragmatismo, rompendo com o fazer profissional sem reflexão, estimulando-se a produção de conhecimento - entendendo este em seu caráter dialético, ou seja, como processo inacabado, em permanente construção e reconstrução.

\section{CONSIDERAÇÕES FINAIS}

Ao adotar um modelo de ensino/aprendizagem que seja efetivado no cotidiano das práticas em saúde, faz-se necessário a adoção de estratégias de problematização das práticas profissionais reafirmando sua capacidade de oferecer e estruturar um modelo de cuidado que considere as várias dimensões e necessidades de saúde das pessoas, dos coletivos e das populações e o exercício do controle social em saúde.

Considerando que as ações voltadas para a formação profissional devem privilegiar a construção de estratégias, técnicas e formação de habilidades, ressaltamos o cuidado de não reduzi-la a uma dimensão exclusiva do como fazer. O processo formativo deve assumir o compromisso de ultrapassar estes limites e garantir uma formação crítica, reflexiva e contextualizada. Do contrário, estará fadada a capacitar profissionais que, aparentemente sabem fazer, mas que não conseguem explicar as razões, o conteúdo, a direção social e os efeitos de seu trabalho na sociedade.

Sendo assim, apontamos para um grande desafio posto aos assistentes sociais na organização das práticas em saúde e no desenvolvimento das ações de ensino em serviço, cujo exercício profissional coadune com o Projeto Ético Político Profissional. Desafio este que repousa no compromisso com práticas que caminhem na direção da 
efetivação das propostas da Reforma Sanitária, no sentido da construção de estratégias coletivas de enfrentamento para as expressões da questão social no âmbito da saúde e no fortalecimento da luta pela garantia e ampliação dos direitos sociais, tendo como horizonte a construção de uma sociedade radicalmente democrática.

\section{REFERÊNCIAS}

ABRAHÃO, A. L. Tecnologia: conceito e relações com o trabalho em saúde. In. FONSECA, A. F.; STAUFFER, A. B. O processo histórico do trabalho em saúde. Rio de Janeiro: EPSJV/Fiocruz, 2007.

ABEPSS. Lei de Diretrizes Curriculares. Brasília, 1996.

BRASIL. Lei 8.080/90. Dispõe sobre as condições para a promoção, proteção e recuperação da saúde. Brasília, 1990.

BRASIL. Lei 8662/93. Lei de Regulamentação da Profissão de Assistente Social. Brasília, 1993.

BRASIL. Lei 11.129/05. Institui as residências multiprofissionais e em área profissional da saúde. Brasília, 2005.

BRASIL. Situação do Câncer no Brasil. Rio de Janeiro: INCA, 2006.

BRAVO, M. I. S.; MATOS, M. C. Projeto Ético Político do Serviço Social e sua relação com a Reforma Sanitária: elementos para o debate. In: MOTA, A. E. et al. Serviço Social e Saúde: formação e trabalho profissional. São Paulo: Cortez, 2006. BRAVO, M. I. S. Política de Saúde no Brasil. In: Ana Elizabete Mota et alli Serviço Social e Saúde: formação e trabalho profissional. São Paulo: Cortez, 2006.

CNS. Resolução CNS no ${ }^{\mathbf{2 8}}$ /1998. Dispõe sobre as profissões da saúde.

CNRMS. Resolução CNRMS no 2/2012. Institui as diretrizes gerais para a criação e operacionalização dos Programas de Residência Multiprofissional e em Área Profissional da Saúde. Brasília, 2012.

CFESS. Código de Ética Profissional do Assistente Social. Brasília: CFESS, 1993. CFESS. Parâmetros para Atuação dos Assistentes Sociais na Política de Saúde. Brasília: CFESS, 2010.

DONNANGELO, M. C. F. Saúde e Sociedade. São Paulo: Duas Cidades, 1976. INCA. Estimativa 2012. Instituto Nacional de Câncer José Alencar Gomes da Silva. Rio de Janeiro: INCA, 2011. 
INCA. Plano de Curso do Programa de Residência Multiprofissional em Oncologia. Instituto Nacional de Câncer José Alencar Gomes da Silva. Rio de Janeiro: INCA, 2012.

NOGUEIRA, V. M. R.; MIOTO, R. C. T. Desafios Atuais do SUS e as exigências para os assistentes sociais. In: MOTA, A.E. et al. Serviço Social e Saúde: formação e trabalho profissional. São Paulo: Cortez, 2006.

IAMAMOTO, M. V. As dimensões ético-políticas e teórico-metodológicas no Serviço Social contemporâneo. In: MOTA, A.E. et al. Serviço Social e Saúde: formação e trabalho profissional. São Paulo: Cortez, 2006.

TEIXEIRA, S. M. F. Descentralização dos serviços de saúde: dimensões analíticas. Cadernos da IX Conferência Nacional de Saúde. Volume I. Brasília: Unb, 1992, p. 27- 37.

WHO. Word Health Organization. World Cancer Report 2008. Lyon: WHO, 2008. 